American Journal of Pharmacology and Toxicology 2(3): 111-115, 2007

ISSN: 1557-4962

(C) 2007 Science Publications

\title{
Cardiovascular Effect of Capparis spinosa Aqueous Extract. Part III: Antihypertensive Effect in Spontaneously Hypertensive Rats
}

\author{
${ }^{1}$ Zeggwagh Naoufel Ali, ${ }^{1}$ Mohamed Eddouks, ${ }^{2}$ Jean Baptiste Michel, ${ }^{3}$ Thierry Sulpice and ${ }^{1}$ Lhoussain Hajji \\ ${ }^{1}$ UFR PNPE, BP.21, Errachidia, 52000, Morocco \\ ${ }^{2}$ U460 INSERM, Faculty of Medicine Xavier Bichat, Paris, France \\ ${ }^{3}$ Physiogenex, Toulouse, France
}

\begin{abstract}
This study aims to evaluate the hypotensive activity of Capparis spinosa Aqueous Extract (CSAE) in Spontaneously Hypertensive (SH) rats. CSAE was lyophilised and administrated daily at a dose of $150 \mathrm{mg} \mathrm{kg}^{-1}$ for 20 days. CSAE administration produced a significant reduction in systolic blood pressure after eight days of oral administration $(\mathrm{p}<0.01)$, a sustained reduction was observed at the end of the end treatment $(p<0.01)$. Heart rate remained unchanged during 20 days of CSAE oral administration. In addition, CSAE administration produced a significant increase in urinary output $(p<0.01)$ and Glomerular Filtration Rate $(G F R)(p<0.01)$ at the eighth day of treatment. Urinary electrolytes excretion was also modified during 20 days of CSAE administration, a significant increase in urinary sodium and potassium excretion was observed from the fourth day $(p<0.01)$ to twentieth day $(p<0.001)$. However, urinary chloride excretion was increased from the eighth day $(p<0.01)$ to the end of treatment $(p<0.001)$. The observed hypotensive effect seems to be independent of renin angiotensin system since the CSAE did not modify the plasma angiotensin converting enzyme and renin activities $(p>0.05)$ after 20 days of oral administration. We conclude that CSAE possess antihypertensive activity in SH rats and the underlying mechanism seems to be mediated via at least an increase in urinary and electrolytes output.
\end{abstract}

Key words: Blood pressure, aqueous extract, diuretic activity, renin angiotensin system

\section{INTRODUCTION}

Hypertension is a serious public health problem worldwide; more than $20 \%$ of the world's population suffers from high blood pressure ${ }^{[1]}$. Angiotensin converting enzyme is the key enzyme in the regulation of the Renin Angiotensin System (RAS) that regulate blood pressure as well as salt and water balance. Inhibition of ACE plays a beneficial role in the reduction of both blood pressure and hypertensive organ damage ${ }^{[1]}$. Combination of ACE inhibitors and diuretic drugs demonstrated a potent clinical efficiency in the reduction of blood pressure ${ }^{[2]}$.

Natural products may be alternative solution in the treatment of human hypertension. Various plants extract and products demonstrated potent in vivo hypotensive effect in Spontaneously Hypertensive ( $\mathrm{SH}$ ) rat, which is a valid animal model of essential hypertension $^{[3]}$

Inhibition of ACE or increasing diuresis and renal electrolytes excretion seems to be the most pharmacological mechanism involved in the hypotensive mechanism of plants after oral administration to $\mathrm{SHR}^{[4,5]}$.
Ethnophamacological survey realized in the South Est of Morocco clearly established the intensive use of medicinal plants in the treatment of diabetes and cardiovascular diseases $^{[6]}$. Capparis spinosa (CS) is a plant belonging to Capparidaceae family traditionally used as aqueous decoction on the treatment of hypertension $^{[7]}$. As there is no scientific report concerning the hypotensive effect of CS aqueous extract, we carry out this work in order to evaluate the effect of Cappris spinosa Aqueous Extract (CSAE) oral administration on SHR. Special attention was made to the change affecting diuresis, electrolytes, ACE and plasma renin activity during 20 days of treatment.

\section{MATERIALS AND METHODS}

Plant material: Specimens of Cs (Capparidaceae) were collected from the Tafilalet region (semi-arid area) of Morocco in May-June 2001 and air-dried at $40^{\circ} \mathrm{C}$. The plant was previously identified and authenticated by Pr. M. Rejdali (Agronomy and Veterinary Institute, Rabat) and a voucher specimen (ME 60) was deposited at the herbarium of the Faculty of Sciences and Techniques Errachidia.

Corresponding Author: Mohamed Eddouks, BP 21, Errachidia, 52000, Morocco Tel: +21255574497 Fax: +21255574485 
Preparation of the aqueous extract: About $1 \mathrm{~g}$ of powdered fruits mixed with $100 \mathrm{ml}$ distilled water were boiled for $10 \mathrm{~min}$ and then cooled for $15 \mathrm{~min}$. Thereafter, the aqueous extract was filtered using a Millipore filter (Millipore $0.2 \mathrm{~mm}$, St Quentin en Yvelines, France) to remove particulate matter. The filtrate was then freeze-dried and the desired dose (mg of lyophilized aqueous extract of CS fruits per $\mathrm{kg}$ body weight) was then prepared and reconstituted in saline just before administration. The extract was green coloured with a percent yield of $14 \%$, its average osmolarity was $32 \mathrm{mOsm}, \mathrm{pH} 6.5$ and with a very low viscosity.

Animals: Experiments were performed in spontaneously hypertensive $(\mathrm{SH})$ rats male rats (GENEST Saint ISLE-France) weighing between 210 and $260 \mathrm{~g}$, housing at $23 \pm 1^{\circ} \mathrm{C}$ with $12 \mathrm{~h}$ light $/ 12 \mathrm{~h}$ dark photoperiod, with food (standard rat diet) and water ad libitum. Animals were assigned to two different groups of six rats each $(n=6)$ and treated as follows: the first group received distilled water and served as control group, the second received the aqueous CS extract at a dose of $140 \mathrm{mg} \mathrm{kg}^{-1}$. The rats were given the drug solutions (CS or distilled water) by oral gavage at a volume of $10 \mathrm{~mL} \mathrm{~kg}$-1 once a day during three weeks. The influence of circadian rhythms was avoided by starting all experiments at 10:00 a.m. immediately after gavage, the rats were individually housed in metabolic cages and allowed an ad libitum access to water and food throughout the period of treatment. The animals were maintained on a $12 \mathrm{~h}$ light $/ 12 \mathrm{~h}$ dark cycle during this study.

Parameters: Urine was collected in graduated cylinders at each four days after daily oral administration and its volume and electrolytes content were measured. Arterial blood pressure and heart rate of the conscious animals were measured using a blood pressure recorder (Ugo basile biological research apparatus APELEX Comerio-(va)-Italy).

The systolic blood pressure and heart rate were measured before starting the experiments each four days during 20 days. The mean bloodless pressure recording was avoided at the same time in order to discard the influence of the circadian rhythm.

Blood samples for plasma electrolytes, creatinine, $\mathrm{ACE}$ and renin activity determinations were retrieved from all animals in conscious state from the retroorbital sinus. Blood samples were centrifuged at $4000 \mathrm{rpm}$ for $10 \mathrm{~min}$ at $4{ }^{\circ} \mathrm{C}$ and then the plasma was then recuperated.
Biochemical analysis: Creatinine levels were evaluated in plasma and urine by colorimetric methods, according to the manufacturer's protocol (Boerhinger, Germany) using a spectrophotometer (HITACHI Model U-2001). Sodium, potassium, chloride, creatinine levels were determined in plasma and urine samples using an autoanalyser (AU 400 Olympus France). ACE activity determination was based on the technique described by Cushman and Cheung ${ }^{[8]}$. Plasma active renin was measured by immunoradiometric assay as previously described $^{[9]}$.

Statistical analysis: Data were analyzed by ANOVA for repeated measures, followed by a paired test if significant. Data were expressed as means \pm SD. Results were considered significant when $p<0.05$.

\section{RESULTS}

Effect of aqueous CS extract (CSAE) administration on Systolic Blood Pressure (SBP) and heart rate (HR): Figure 1 shows the effect of oral administration of aqueous CS extract at a dose of $140 \mathrm{mg} \mathrm{kg}^{-1}$ on systolic blood pressure during 20 days of treatment. A significant decrease on SBP was observed after eight days of CSAE administration $(\mathrm{p}<0.01)$ leading to $13.5 \pm 2.63 \mathrm{mmHg}$ reduction of baseline systolic blood pressure. Additional reduction was observed at the eighth and sixtieth day of treatment $(p<0.01)$.

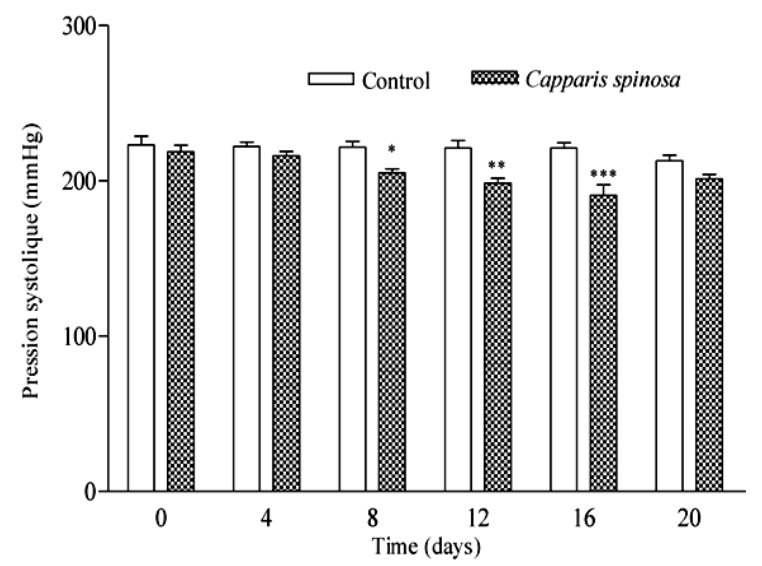

Fig. 1: Effect of oral administration of CSAE at a dose of $150 \mathrm{mg} \mathrm{kg}$ on systolic blood pressure $(\mathrm{mmHg})$ on $\mathrm{SH}$ rats. Data are expressed as means \pm S.E.M for six determinations. *: $\mathrm{p}<0.05 * *: \quad \mathrm{p}<0.01, \quad * * *: \quad \mathrm{p}<0.001$ when compared with respective control values 


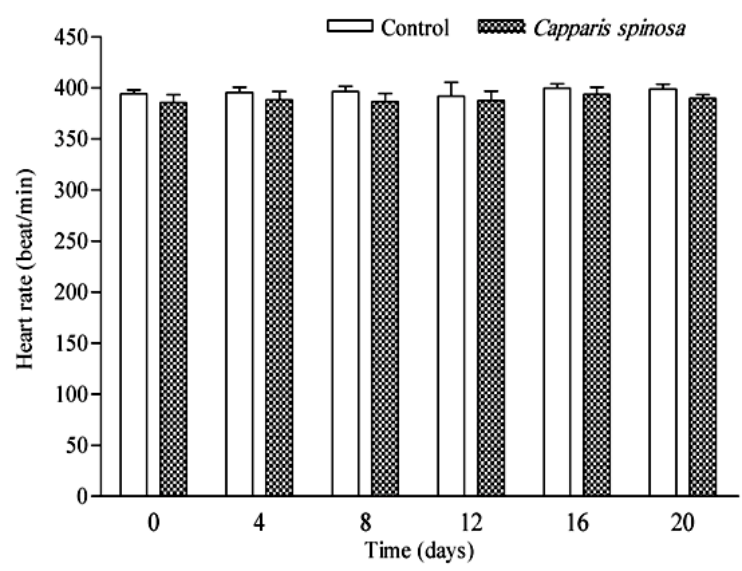

Fig. 2: Effect of oral administration of CSAE at a dose of $150 \mathrm{mg} \mathrm{kg}^{-1}$ on heart rate (beat/min) in $\mathrm{SH}$ rats. Data are expressed as means \pm S.E.M for six determinations. *: $\mathrm{p}<0.05 * *: \mathrm{p}<0.01, * * *$ : $\mathrm{p}<0.001$ when compared with respective control values

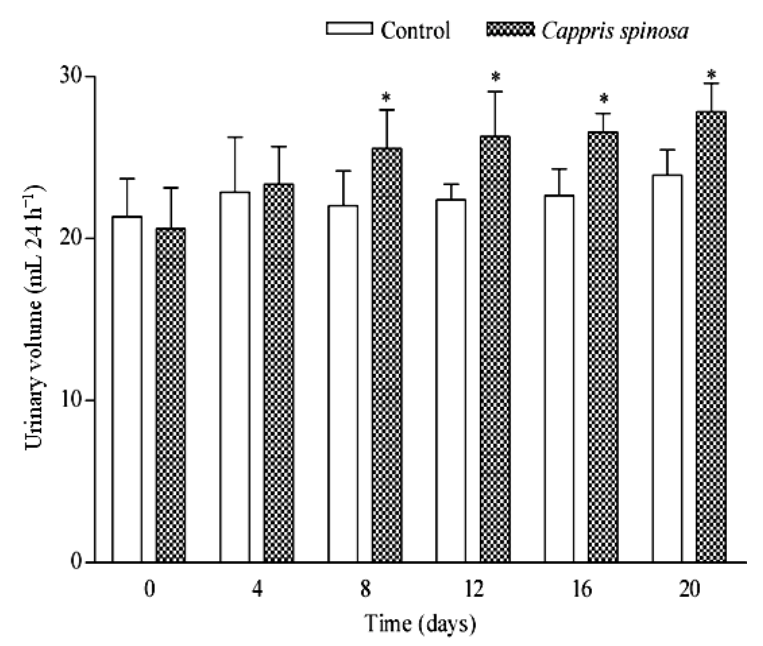

Fig. 3: Effect of oral administration of CSAE at a dose of $150 \mathrm{mg} \mathrm{kg}^{-1}$ on urine output $\left(\mathrm{mL} 24 \mathrm{~h}^{-1}\right)$ in $\mathrm{SH}$ rats. Data are expressed as means \pm S.E.M for six determinations. $*$ : $\mathrm{p}<0.05 * *$ : $\mathrm{p}<0.01$, $* * *: \mathrm{p}<0.001$ when compared with respective control values

No significant change in heart rate was observed during 20 days of CSAE administration as it is shown in Fig. 2.

Effect of CSAE administration on urine output, glomerular filtration rate and urinary electrolytes: Significant increase in urine output was observed from the eighth day to the end of treatment $(\mathrm{p}<0.01)$ (Fig. 3).

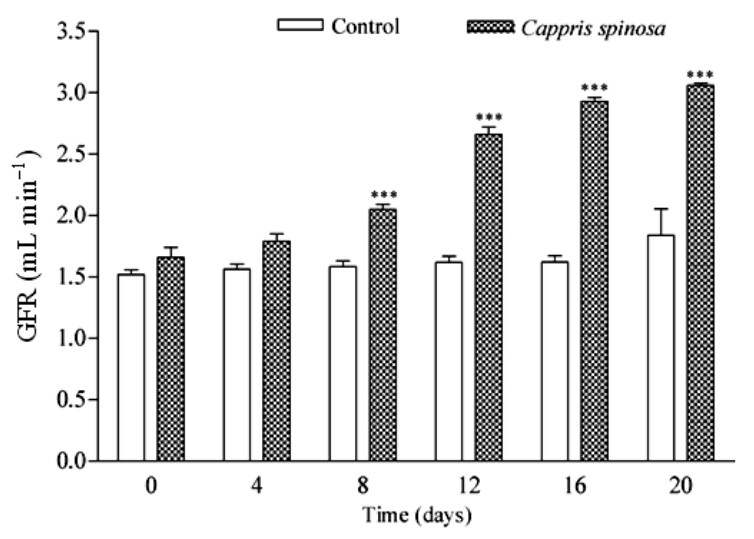

Fig. 4: Effect of oral administration of CSAE at a dose of $150 \mathrm{mg} \mathrm{kg}^{-1}$ on glomerular filtration rate $\left(\mathrm{mL} \mathrm{min}^{-1}\right)$ in $\mathrm{SH}$ rats. Data are expressed as means \pm SEM for six determinations. $*: p<0.05$ $* *: \mathrm{p}<0.01, * * *: \mathrm{p}<0.001$ when compared with respective control values

Table 1: Effect of oral administration of CSAE at a dose of $150 \mathrm{mg} \mathrm{kg}^{-1}$ on plasma sodium, potassium and chlorides $\left(\mathrm{mmol} \mathrm{L}^{-1}\right)$ after 20 days of treatment

\begin{tabular}{llll}
\hline Treatment & Sodium & Potassium & Chloride \\
\hline Control & & & \\
Day 0 & $167.80 \pm 2.02$ & $122 \pm 1.02$ & $6.03 \pm 0.93$ \\
Day 20 & $168.01 \pm 1.83^{\mathrm{NS}}$ & $123 \pm 2.03^{\mathrm{NS}}$ & $6.13 \pm 0.12^{\mathrm{NS}}$ \\
CSAE & & & \\
Day 0 & $166.20 \pm 2.13$ & $120.83 \pm 0.13$ & $6.12 \pm 2.01$ \\
Day 20 & $165.30 \pm 1.14$ & $121.00 \pm 1.13$ & $6.09 \pm 1.63$ \\
\hline
\end{tabular}

Data are expressed as means \pm SEM for six determinations. NS: Not significant when compared to the respective control values

However, no change in urinary output was observed in control group (Fig. 3). Glomerular Filtration Rate (GFR) showed a significant increase $(p<0.01)$ from the eighth to the end of treatment $(p<0.01)$ (Fig. 4). Sodium urinary excretion showed a significant increase from the fourth day $(p<0.01)$ of treatment to the end of treatment $(p<0.001)$ (Fig. 5a). Significant and gradual increase in urinary potassium excretion was observed in the fourth day $(p<0.001)$, further increase was observed at the end of treatment $(\mathrm{p}<0.001)$ (Fig. 5b). However, urinary chloride excretion was increased after 12 days of treatment $(\mathrm{p}<0.01)$ (Fig. $5 \mathrm{c})$.

Effect of CSAE administration in plasma electrolytes levels: Table 1 shows change in plasma electrolytes levels in the start and after 20 days of CSAE administration. Oral administration of CSAE did not change plasma electrolytes levels $(p>0.05)$. 

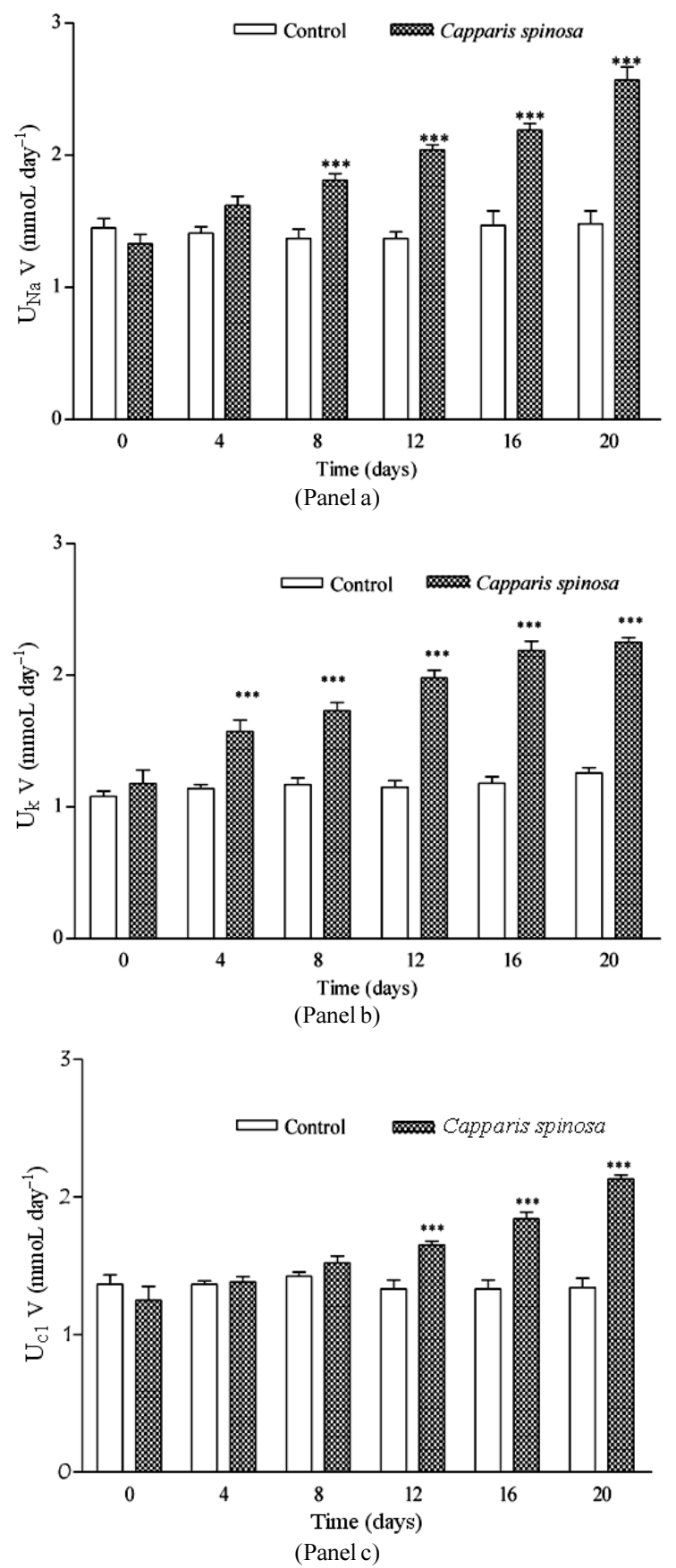

Fig. 5: Effect of oral administration of CSAE at a dose of $150 \mathrm{mg} \mathrm{kg}^{-1}$ on urinary excretion of sodium (UNaV) (Panel a), Potassium (UKV) (Panel b) and chloride (UClV) (Panel b). Data are expressed as means \pm SEM for six determinations. *: $\mathrm{p}<0.05$ **: $\mathrm{p}<0.01, * * *$ : $\mathrm{p}<0.001$ when compared with respective control values
Table 2: Effect of oral administration of CSAE at a dose of $150 \mathrm{mg} \mathrm{kg}^{-1}$ on plasma ACE activity $\left(\mathrm{mmol} \mathrm{mL}^{-1} \mathrm{~min}^{-1}\right)$ an plasma renin activity $\left(\mathrm{ng} \mathrm{mL} \mathrm{m}^{-1} \mathrm{~h}^{-1}\right)$ after days of treatment

\begin{tabular}{lll}
\hline Treatment & Plasma ACE activity & Plasma renin activity \\
\hline Control & $103.25 \pm 2.06$ & $10.93 \pm 0.06$ \\
Day 0 & $102.06 \pm 1.96$ & $10.73 \pm 0.11$ \\
Day 20 & & \\
CSAE & $98.120 \pm 1.91$ & $11.73 \pm 0.13$ \\
Day 0 & $101.02 \pm 2.74^{\mathrm{NS}}$ & $11.61 \pm 0,25^{\mathrm{NS}}$ \\
Day 20 &
\end{tabular}

Data are expressed as means \pm SEM for six determinations. NS: Not significant when compared to the respective control values

Effect of CSAE on plasma $\mathrm{ACE}$ and renin activities: Changes in plasma ACE and renin activities are shown in Table 2. No significant change in plasma ACE and renin activities was observed after 20 days of oral administration of CSAE.

\section{DISCUSSION}

Actually, special attention is made to the discovery of new pharmacological agent from plants ${ }^{[10]}$. In spite of the pharmacological efficiency of antihypertensive drugs, new products inhibiting hypertension organ damage are needed ${ }^{[11]}$. RAS plays a central role in the regulation of arterial blood pressure under normal and elevated blood pressure conditions ${ }^{[1]}$. ACE inhibition and increased urine out put may be beneficial in the reduction of arterial blood pressure in $\mathrm{SH}$ rats ${ }^{[12,13]}$. So, we speculate that CSAE may reduce blood pressure via an inhibition of ACE and or increasing diuresis and renal electrolytes elimination. We focus attention on modification affecting plasma ACE and renin activities as two indicators of ACE inhibition ${ }^{[13]}$.

Our previous investigations demonstrated the hypoglycaemic and hypolipedimic effects of CSAE in streptozotocin-induced diabetic rats ${ }^{[14]}$.

This study aims to evaluate the hypotensive effect of CSAE in SHR. CSAE was lyophilised and orally administered at a dose of $150 \mathrm{mg} \mathrm{kg}^{-1}$ once a day for 20 days.

CSAE significantly reduced $\mathrm{SBP}$ in $\mathrm{SH}$ rats after eight days of oral administration without affecting heart rate. Lepidium sativum and Fraxinus excelsior when orally administrated at a dose of $20 \mathrm{mg} \mathrm{kg}^{-1}$ have been demonstrated to be similar but with less potent hypotensive activity in $\mathrm{SH}$ rats ${ }^{[15]}$. However, other plant extract reduced both arterial blood pressure and heart rate $^{[10,16,17]}$. CSAE may reduce blood pressure via a peripheral vasodilatation as we observed after intravenous injection of CSAE in normal rats (unpublished data).

GFR showed significant increase after CSAE treatment, this may be due to a renal afferent arteriole vasodilatation $^{[4,17]}$ or an impairment of an auto-regulatory renal mechanism by increasing the $\mathrm{Na}^{+}$filtered load. 
Furthermore, an increase in diuresis and urinary sodium, potassium and chloride excretion was observed from the eighth day of CSAE treatment corresponding to the observed fail in arterial blood pressure. The increase in urinary electrolytes excretion may be a result of renal $\mathrm{Na}^{+} / \mathrm{K}^{+} / 2 \mathrm{Cl}$ pump inhibition. Plant potassium content may also be responsible of the diuretic activity of plant extract .

Abnormal plasma ACE activity has been reported in SHR. Twenty days of CSAE did not change plasma ACE and rennin activities. Providing that the hypotensive effect of CSAE is independent of RAS. Previous studies demonstrated a potent inhibition of plasma ACE activity after oral administration of aqueous plants extract.

The underlying mechanism of CSAE antihypertensive activity seems to be due to the diuretic and natriuretic activities as the hypotensive effect was maintained during 15 days. Possible peripheral vasodilatation may exacerbate this hypotensive effect. However, it is not excluded that CSAE may reduce blood pressure via an angiotensin II antagonism or alpha adrenergic blockade mechanism.

The use of isolated aortic ring manipulation may provide ample information in the vasorelaxant mechanism of CSAE.

We conclude that aqueous extract of CSAE was effective in decreasing blood pressure and increasing water and electrolytes excretion. These results suggest that CSAE can improve hypertension with no influence on cardiac rate. Therefore, these findings support the use of CSAE decoction by the Moroccan population for the treatment of hypertension.

\section{REFERENCES}

1. Caceres, A., L.M. Giron and A.M. Martinez, 1987. Diuretic activity of plants used for the treatment of urinary ailments in guatemala. J. Ethnopharmacol., 19: 233-245.

2. Zamboli, P., L. De Nicola, R. Minutolo, V. Bertino, F. Catapano and G. Conte, 2006. Management of hypertension in chronic kidney disease. Curr. Hypertens. Rep., 8: 497-501.

3. Eddouks, M., M. Maghrani, N.A. Zeggwagh, M. Haloui and J.B. Michel, 2005. Fraxinus excelsior L. evokes a hypotensive action in normal and spontaneously hypertensive rats. J. Ethnopharmacol., 99: 49-54.

4. Herrera-Arellano, A., J. Miranda-Sanchez, P. AvilaCastro, S. Herrera-Alvarez, J.E. Jimenez-Ferrer, A. Zamilpa, R. Roman-Ramos, H. Ponce-Monter and J. Tortoriello, 2007. Clinical effects produced by a standardized herbal medicinal product of Hibiscus sabdariffa on patients with hypertension. A randomized, double-blind, lisinopril-controlled clinical trial. Planta Med., 73: 6-12.
5. Inokuchi, J., H. Okabe, T. Yamauchi, A. Nagamatsu, G. Nonaka and I. Nishioka, 1986. Antihypertensive substance in seeds of Areca catechu L. Life Sci., 38: 1375-1382.

6. Eddouks, M., M. Maghrani, A. Lemhadri, M.L. Ouahidi and H. Jouad, 2002. Ethnopharmacological survey of medicinal plants used for the treatment of diabetes mellitus, hypertension and cardiac diseases in the south-east region of Morocco (Tafilalet). J. Ethnopharmacol., 82: 97-103.

7. Cushman, D.W. and H.S. Cheung, 1971. Spectrophotometric assay and propreties of the angiotensin-converting enzyme of rabbit. Lung. Biochem. Pharmacol., 20: 1637-1648.

8. Freildland, J. and E. Silverstein, 1976. A sensitive fluorimetric assay for serum angiotensin-converting enzyme. Am. J. Clin. Pathol., 66: 416-424.

9. Rates, S.M.K., 2001. Plants as source of drugs. Toxicon, 39: 603-613.

10. Bakris, G.L. and G.A. Mensah, 2003. Pathogenesis and clinical physiology of hypertension. Curr. Prob. Cardiol., 28: 137-155.

11. Michel, J.B., 2004. Renin angiotensine-system and vascular remodeling. Med. Sci., 20: 409-413.

12. Maghrani, M., N.A. Zeggwagh, A. Lemhadri, M. El Amraoui, J.B. Michel and M. Eddouks, 2004. Study of the hypoglycaemic activity of Fraxinus excelsior and Silybum marianum in an animal model of type 1 diabetes mellitus. J. Ethnopharmacol., 91: 309-316.

13. Maghrani, M., N.A. Zeggwagh, J.B. Michel and M. Eddouks, 2005. Antihypertensive effect of Lepidium sativum L. in spontaneously hypertensive rats. J. Ethnopharmacol., 100: 193-197.

14. Hattori, T. and P.L. Wang, 2006. Involvement of $\mathrm{Na}(+)-\mathrm{K}(+)-2 \mathrm{Cl}(-)$ cotransporters in hypertonicityinduced rise in intracellular calcium concentration. Int. J. Neurosci., 116: 1501-1507.

15. Haloui, M., L. Louedec, J.B. Michel and B. Lyoussi, 2000. Experimental diuretic effects of Rosmarinus officinalis and Centaurium erythraea. J. Ethnopharmacol., 71: 465-472.

16. Lerman, L.O., A.R. Chade, V. Sica and C. Napoli, 2005. Animal models of hypertension: An overview. J. Lab. Clin. Med., 146: 160-169.

17. Liu, J.C., F.L. Hsu, J.C. Tsai, P. Chan, J.Y. Liu, G.N. Thomas, B. Tomlinson, M.Y. Lo and J.Y. Lin, 2003. Antihypertensive effects of tannins isolated from traditional Chinese herbs as nonspecific inhibitors of angiontensin converting enzyme. Life Sci., 73: 1543-1555. 